\title{
A retrospective analysis of safety and efficacy of weekly nab-paclitaxel as second-line chemotherapy in elderly patients with advanced squamous non-small-cell lung carcinoma
}

\author{
This article was published in the following Dove Press journal: \\ Clinical Interventions in Aging \\ 19 February 2016 \\ Number of times this article has been viewed
}

\author{
Feng Jin ${ }^{1,2}$ \\ Hui Zhul,2 \\ Fang Shi, ${ }^{1,2}$ \\ Li Kong ${ }^{1,2}$ \\ Jinming $Y u^{1,2}$ \\ 'Department of Radiation Oncology, \\ Shandong Cancer Hospital and \\ Institute, ${ }^{2}$ Shandong Academy of \\ Medical Sciences, University of Jinan, \\ Jinan, Shandong Province, People's \\ Republic of China
}

\begin{abstract}
Purpose: The aim of this retrospective study was to investigate the anticancer effect and toxicity of weekly administered nab-paclitaxel as a second-line chemotherapy in elderly patients with relapsed squamous non-small-cell lung cancer (NSCLC).

Patients and methods: We retrospectively reviewed the treatment of 42 elderly patients with relapsed squamous NSCLC, who received nab-paclitaxel monotherapy as a second-line treatment from January 2010 to March 2014. A dose of $100 \mathrm{mg} / \mathrm{m}^{2}$ nab-paclitaxel was administered weekly on days 1,8 , and 15 , followed by 1 week of rest. The protocol was maintained for at least two cycles.
\end{abstract}

Results: The overall response rate (ORR) and the disease control rate (DCR) were $21.43 \%$ (9/42) and 47.62\% (20/42), respectively. The median progression-free survival (PFS) and overall survival (OS) were 6.6 and 10.9 months, respectively. In the subgroup analysis, there was no significant difference in ORR, DCR, PFS, and OS, accounting for the first-line therapy factors (taxane agent, radiotherapy, or surgery). There was a statistically significant difference in DCR for stages III and IV ( $62.96 \%$ vs $20 \%, P=0.008)$, but there was no such difference in either PFS or OS. The ORR of 29 patients receiving more than three cycles of treatment was higher than that of those receiving less than three cycles of treatment ( $31.03 \%$ vs $0 \%, P=0.038$ ), and there was a significant difference in PFS (7.6 vs 4.9 months, $P=0.004$ ) and OS ( 11.7 vs 8.9 months, $P=0.002$ ). No hypersensitivity reactions or treatment-related grade 4 adverse events were reported.

Conclusion: Nab-paclitaxel monotherapy administered weekly at a dose of $100 \mathrm{mg} / \mathrm{m}^{2}$ is shown to be an effective and safe regimen for elderly patients with relapsed squamous NSCLC, especially for patients with stage III disease or good performance status.

Keywords: nab-paclitaxel, squamous, non-small-cell lung cancer, second line, elderly

\section{Introduction}

Approximately $90 \%$ of all lung cancers are non-small-cell lung cancer (NSCLC), with $\sim 25 \%-30 \%$ of NSCLC being of the squamous subtype. ${ }^{1}$ To date, no agents have been specifically approved for the treatment of squamous NSCLC. Most patients with NSCLC present with advanced or metastatic disease at the time of diagnosis, and the 5 -year survival for these patients is only $3.9 \% .^{2}$ The primary therapy is palliative chemotherapy, for which platinum-based chemotherapy is the only option. Although cytotoxic chemotherapy as a first-line treatment may delay disease progression and prolong survival, almost all patients develop progressive disease and require additional therapies. Recently, substantial advances have been made in treating nonsquamous
Correspondence: Jinming Yu

Department of Radiation Oncology, Shandong Cancer Hospital and Institute, Jiyan Road 440, Jinan 250II7, Shandong Province, People's Republic of China

Tel +8653187984729

Fax +86 53। 87984079

Email sdyujinming@sina.com
Clinical Interventions in Aging 2016: I I 167-173

(c) (1) (8) ๑ 2016 jin et al. This work is pulished and licensed by Dove Medical Press Limited. The full terms of this license are available at https://www.dovepress.com/terms.php

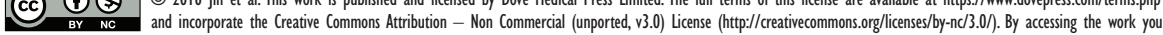
hereby accept the Terms. Non-commercial uses of the work are permitted without any further permission from Dove Medical Press Limited, provided the work is properly attributed. For permission for commercial use of this work, please see paragraphs 4.2 and 5 of our Terms (https://www.doveperess.com/terms.php).
Dovepress

http://dx.doi.org/10.2147/CIA.S97363 \section{7}


NSCLC, but there has been little progress in the treatment of the squamous subtype.

With increasing life expectancy worldwide, there has been a notable increase in the incidence of lung cancer owing to the associated cumulative increase in the risk of cancer with age. For all patients diagnosed in 1975-2010, the median age was 70 years. $^{2}$ In elderly patients with a good performance status (PS) of $0-1$, doublet chemotherapy, including platinum, should not be excluded, especially for patients of age 70-75 years without comorbidities. ${ }^{3}$ However, evidence suggests that patients $>65$ years old are likely to metabolize chemotherapeutic agents more slowly than do younger patients, resulting in higher drug exposure levels and more serious adverse events (AEs). ${ }^{4}$ Concern about AEs may lead clinicians to reduce treatment dose or to interrupt treatment, which could in turn compromise efficacy. Therefore, more effective and better tolerated therapeutic options are needed for elderly patients with NSCLC.

The National Comprehensive Cancer Network Guidelines authorize three drugs (docetaxel, pemetrexed, and erlotinib) for second-line therapy in patients with advanced NSCLC who have been previously treated with at least one line of a platinum-based combination chemotherapy. Docetaxel is considered more effective than pemetrexed and erlotinib for the second-line treatment of advanced or metastatic squamous NSCLC. ${ }^{5,6}$ Despite the clinical activity, the use of docetaxel could be limited by significant toxicities observed in treated patients, such as hypersensitivity reactions and peripheral neuropathy. ${ }^{7}$

Nab-paclitaxel (Abraxane; Abraxis BioScience, Inc., Santa Monica, CA, USA) is a formulation of $130 \mathrm{~nm}$ albumin-bound paclitaxel particles. It was developed to improve the therapeutic index of paclitaxel, which as a single agent had exhibited promising efficacy and tolerability in Phase I/II studies in stage IV NSCLC. ${ }^{8}$ The same result had been achieved in combination with carboplatin for elderly patients. ${ }^{9}$ Furthermore, single-agent nab-paclitaxel as a second-line chemotherapy was approved for the treatment of metastatic breast cancer and was shown to be effective and well tolerated. ${ }^{10}$ Nonetheless, little is known about the effect of nab-paclitaxel as a second-line therapy targeting squamous NSCLC at an advanced or metastatic stage.

Although there has been no clinical trial, specifically in elderly patients, of second-line therapy for squamous NSCLC, preliminary data indicate roles for nab-paclitaxel as a single agent for the first-line or third-line treatment of advanced or metastatic NSCLC. ${ }^{11,12}$ The purpose of this retrospective study was to investigate the anticancer effect and toxicity of weekly administered nab-paclitaxel as a second-line chemotherapy in elderly patients with advanced or metastatic squamous NSCLC who had failed conventional therapy.

\section{Materials and methods}

All patients met the following inclusion criteria: 1) they had a histologic or cytologic diagnosis of stage III or IV squamous NSCLC, 2) they had previously received no less than two cycles of first-line platinum-based doublet chemotherapy without nab-paclitaxel, but the disease progressed, 3) they were older than 65 years, 4) they had an Eastern Cooperative Oncology Group PS $\leq 2,5$ ) they had not received third-line chemotherapy, and 6) they had measurable disease as defined by Response Evaluation Criteria in Solid Tumors (RECIST). ${ }^{13}$ Patients were excluded if they had symptomatic brain metastases or preexisting peripheral neuropathy (grade 1 or higher). We could not evaluate elderly patients by comprehensive geriatric assessment due to some patients with unknown sociodemographic factors. Because this was a retrospective study, informed consent was not required. The Institutional Review Board of Shandong Cancer Hospital approved the study.

Nab-paclitaxel was administered weekly on days 1, 8, and 15 , followed by 1 week of rest. Treatment was repeated every 4 weeks until disease progression or unacceptable toxicity. A dose of $100 \mathrm{mg} / \mathrm{m}^{2}$ was administered for $\sim 30$ minutes without corticosteroid or antihistamine premedication. The protocol recommended that if patients experienced grade 3 or 4 neutropenia or thrombocytopenia during treatment, they should receive a subcutaneous injection of granulocyte colony-stimulating factor or interleukin-11 to address such hematological toxicities. This protocol was maintained for at least two cycles.

The primary efficacy end point was overall response rate (ORR), defined as the percentage of patients having either a complete response (CR) or a partial response (PR), determined according to the RECIST guidelines. ${ }^{13}$ Secondary efficacy end points included disease control rate (DCR; defined as the percentage of patients with stable disease [SD] for 16 weeks and CR and PR), progression-free survival (PFS; defined as the time from treatment to the objective progression of disease), and overall survival (OS; defined as the time from treatment to death). Response assessments were performed every 8 weeks. All patients had a baseline computed tomography (CT) examination of the chest and a reassessment every two treatment cycles. Hematologic and imaging examinations were routinely performed during treatment with nab-paclitaxel. The safety end points were as follows: 1) the incidence of treatment-related AEs based on 
National Cancer Institute Common Toxicity Criteria Version 2.0, 2) laboratory abnormalities, and 3) serious AEs.

All analyses were performed using the Statistical Package for the Social Sciences 20.0 software. Correlation between clinical features and curative effects was analyzed using a $\chi^{2}$ test. PFS and OS were summarized descriptively, and two-sided 95\% confidence intervals (CIs) were presented. PFS and OS were estimated using the Kaplan-Meier method. Differences were assumed to be significant when a $P$-value of $<0.05$ was achieved.

\section{Results}

\section{Patients}

We retrospectively reviewed 42 patients who received a second-line treatment of nab-paclitaxel for NSCLC from January 2010 to March 2014 in the Shandong Cancer Hospital and Institute, People's Republic of China. The baseline characteristics of patients are presented in Table 1. The median age was 71 years (range: 66-83 years) with 37 (88.1\%) male and five $(11.9 \%)$ female patients. The number of patients with a PS score 0-1 (considered good) was 38 (90.48\%); 31 patients $(73.81 \%)$ had a history of smoking.

Table I Baseline characteristics and previous therapy of 42 patients

\begin{tabular}{|c|c|c|}
\hline Clinical feature & $\mathbf{N}$ & Percentage \\
\hline \multicolumn{3}{|l|}{ Sex } \\
\hline Male & 37 & 88.1 \\
\hline Female & 5 & 11.9 \\
\hline \multicolumn{3}{|l|}{ Age } \\
\hline Median & 71 & \\
\hline $66-75$ years & 34 & 80.95 \\
\hline$>75$ years & 8 & 19.05 \\
\hline \multicolumn{3}{|l|}{ ECOG PS } \\
\hline $0-1$ & 38 & 90.48 \\
\hline 2 & 4 & 9.52 \\
\hline \multicolumn{3}{|l|}{ Smoking status } \\
\hline Current or former smoker & 31 & 73.81 \\
\hline Never smoked & 11 & 26.19 \\
\hline \multicolumn{3}{|l|}{ Clinical stage } \\
\hline Stage III & 27 & 64.29 \\
\hline Stage IIIA & 11 & 26.19 \\
\hline Stage IIIB & 16 & 38.10 \\
\hline Stage IV & 15 & 35.71 \\
\hline \multicolumn{3}{|l|}{ Previous taxane } \\
\hline Yes & 17 & 40.48 \\
\hline No & 25 & 59.52 \\
\hline \multicolumn{3}{|l|}{ Previous radiotherapy } \\
\hline Yes & 18 & 42.86 \\
\hline No & 24 & 57.14 \\
\hline \multicolumn{3}{|l|}{ Previous surgery } \\
\hline Yes & 16 & 38.1 \\
\hline No & 26 & 61.9 \\
\hline
\end{tabular}

Abbreviations: ECOG, Eastern Cooperative Oncology Group; PS, performance status.
There were $27(64.29 \%)$ cases of stage III disease, including eleven (26.19\%) cases of IIIA and 16 (38.1\%) cases of stage IIIB; there were $15(35.71 \%)$ cases of stage IV disease. Seventeen $(40.48 \%)$ patients had previously received a taxane agent, $18(42.86 \%)$ had previously received radiotherapy, and 16 (38.1\%) had previously undergone lung surgery. A total of 159 cycles of treatment were delivered overall, with a median of four cycles per patient (range: 2-6). In the treatment group that received less than three cycles, there were five $(11.9 \%)$ patients who discontinued therapy for financial reasons.

\section{Therapeutic outcome}

Therapeutic effect was evaluated using the RECIST standard:

- CR was not experienced in any case.

- PR was experienced in nine cases.

- SD was experienced in eleven cases.

- Progressive disease was experienced in 22 cases.

The ORR (CR + PR) was 21.43\% (95\% CI =17.31\%$24.21 \%)$, and the DCR (CR + PR + SD) was $47.62 \%(95 \%$ $\mathrm{CI}=43.52 \%-51.24 \%$ ). There was no significant difference in either ORR or DCR for the prognostic factors of sex, age, Eastern Cooperative Oncology Group scores, or smoking status (Table 2). There were 27 cases of ORR (29.63\%) and DCR $(62.96 \%)$ in the patients with stage III disease, and there were 15 cases of ORR (6.67\%) and DCR (20\%) in the patients with stage IV disease. Notably, there was a significant difference in DCR for stage $(P=0.008$; Table 2$)$. For the prognostic factors of related first-line therapy (taxane agent, radiotherapy, or surgery), there was no significant difference in ORR or DCR (Table 3). According to the analysis, the ORR of 29 patients receiving more than three cycles of treatment was higher than that of those receiving less than three cycles (31.03\% vs $0 \%, P=0.038)$, but a similar result was not found in DCR (38.46\% vs 51.72\%, $P=0.426$; Table 4).

Among patients receiving second-line therapy, follow-up showed that the median PFS and OS was 6.6 months $(95 \%$ $\mathrm{CI}=5.118-8.082$; Figure $1 \mathrm{~A})$ and 10.9 months $(95 \%$ $\mathrm{CI}=9.206-12.594$ months; Figure 1B), respectively, and the 1 -year survival rate was $35.71 \%$ (15/42). The median PFS of 17 patients who had previously received a taxane agent was 7.2 months (95\% CI $=4.108-10.292)$, and the median PFS of other patients was 6.4 months $(95 \% \mathrm{CI}=5.258-7.542)$. The median OS of patients who had previously received a taxane agent was 11.2 months $(95 \% \mathrm{CI}=8.78-13.62)$ and of those who had received a nontaxane agent was 10.9 months (95\% CI =8.942-12.858). The median PFS of patients at 
Table 2 Correlation between clinical feature and curative effect of nab-paclitaxel as a second-line treatment on lung squamous carcinoma

\begin{tabular}{|c|c|c|c|c|c|c|c|c|}
\hline Clinical feature & Total (N) & PR & SD & PD & ORR (\%) & $P$-value & DCR (\%) & $P$-value \\
\hline \multicolumn{9}{|l|}{ Sex } \\
\hline Male & 37 & 8 & 10 & 19 & 21.62 & 0.934 & 48.65 & 0.716 \\
\hline Female & 5 & 1 & 1 & 3 & 20 & & 40 & \\
\hline \multicolumn{9}{|l|}{ Age, years } \\
\hline $66-75$ & 34 & 7 & 9 & 18 & 20.59 & 0.784 & 47.06 & 0.881 \\
\hline$>75$ & 8 & 2 & 2 & 4 & 25 & & 50 & \\
\hline \multicolumn{9}{|l|}{ ECOG scores } \\
\hline $0-1$ & 38 & 9 & 10 & 19 & 23.68 & 0.561 & 50 & $0.34 I$ \\
\hline 2 & 4 & 0 & 1 & 3 & 0 & & 25 & \\
\hline \multicolumn{9}{|l|}{ Smoking status } \\
\hline Current or former smoker & 31 & 6 & 9 & 16 & 19.35 & 0.582 & 48.39 & 0.867 \\
\hline Nonsmoker & II & 3 & 2 & 6 & 27.27 & & 45.45 & \\
\hline \multicolumn{9}{|l|}{ Clinical stage } \\
\hline Stage III & 27 & 8 & 9 & 10 & 29.63 & 0.082 & 62.96 & 0.008 \\
\hline Stage IV & 15 & I & 2 & 12 & 6.67 & & 20 & \\
\hline
\end{tabular}

Abbreviations: DCR, disease control rate; ECOG, Eastern Cooperative Oncology Group; PD, progressive disease; PR, partial response; SD, stable disease; ORR, overall response rate.

Table 3 Correlation between previous therapy feature and curative effect of nab-paclitaxel as a second-line treatment on lung squamous carcinoma

\begin{tabular}{|c|c|c|c|c|c|c|c|c|}
\hline Subgroup & Total $(\mathbf{N})$ & PR & SD & PD & ORR (\%) & $P$-value & DCR (\%) & $P$-value \\
\hline \multicolumn{9}{|c|}{ Previous taxane } \\
\hline Yes & 17 & 4 & 4 & 9 & 23.53 & 0.784 & 47.06 & 0.952 \\
\hline No & 25 & 5 & 7 & 13 & 20 & & 48 & \\
\hline \multicolumn{9}{|c|}{ Previous radiotherapy } \\
\hline Yes & 18 & 5 & 6 & 7 & 27.78 & 0.385 & 61.11 & 0.129 \\
\hline No & 24 & 4 & 5 & 15 & 16.67 & & 37.5 & \\
\hline \multicolumn{9}{|c|}{ Previous surgery } \\
\hline Yes & 16 & 4 & 4 & 8 & 25 & 0.658 & 50 & 0.808 \\
\hline No & 26 & 5 & 7 & 14 & 19.23 & & 46.15 & \\
\hline
\end{tabular}

Abbreviations: DCR, disease control rate; PD, progressive disease; PR, partial response; SD, stable disease; ORR, overall response rate.

Table 4 Correlation between chemotherapy cycles and curative effect of nab-paclitaxel as a second-line treatment on lung squamous carcinoma

\begin{tabular}{lllllllll}
\hline Cycles of SL chemotherapy & Total (N) & PR & SD & PD & ORR (\%) & $P$-value & DCR (\%) & $P$-value \\
\hline$<3$ & 13 & 0 & 5 & 8 & 0 & 0.038 & 38.46 & 0.426 \\
$\geq 3$ & 29 & 9 & 6 & 14 & 31.03 & & 51.72 & \\
\hline
\end{tabular}

Abbreviations: DCR, disease control rate; PD, progressive disease; PR, partial response; SD, stable disease; SL, second line; ORR, overall response rate.

A

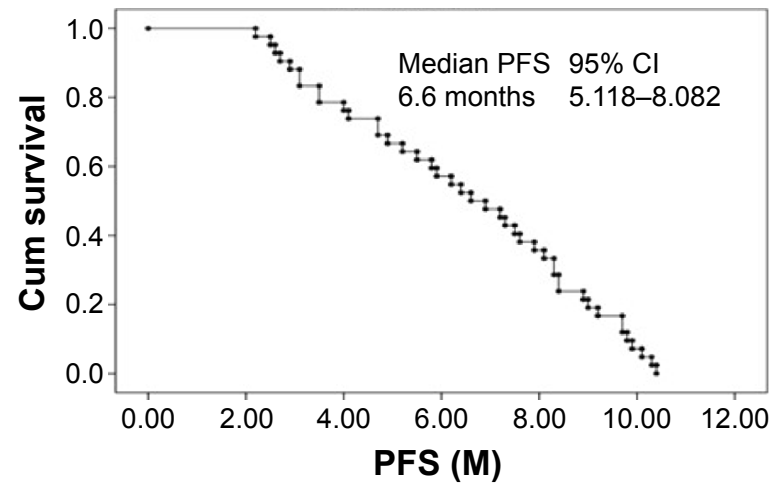

B Survival function

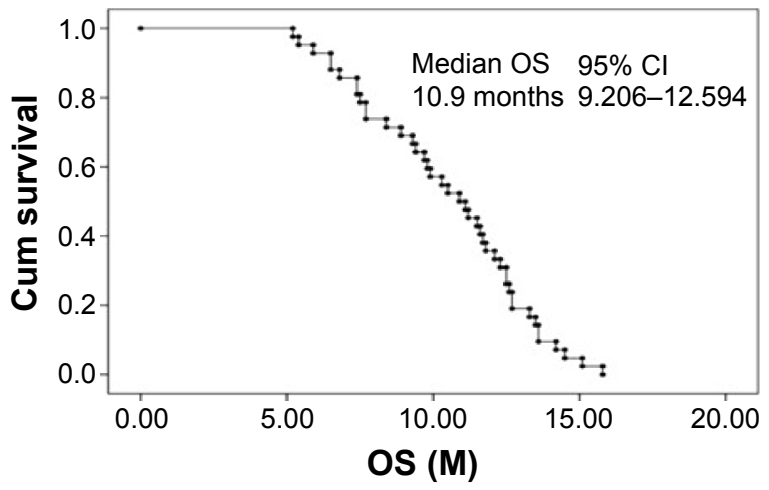

Figure I Kaplan-Meier curve for (A) PFS and (B) OS in the entire cohort of elderly patients with relapsed squamous non-small-cell lung carcinoma ( $\mathrm{n}=42$ ). Abbreviations: $\mathrm{Cl}$, confidence interval; OS, overall survival; PFS, progression-free survival; $\mathrm{M}$, months. 

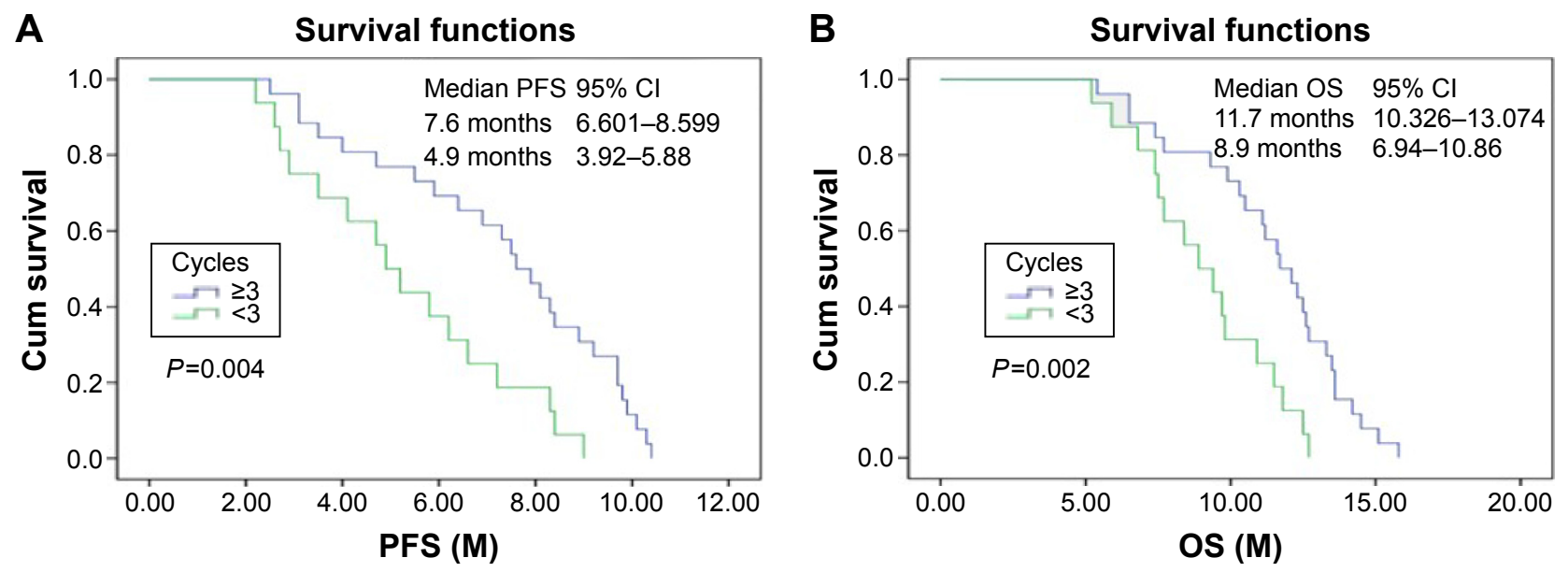

Figure 2 Kaplan-Meier curve for (A) PFS and (B) OS of the patients according to cycles of nab-paclitaxel monotherapy. Abbreviations: $\mathrm{Cl}$, confidence interval; OS, overall survival; PFS, progression-free survival; $\mathrm{M}$, months.

stage III was 7.2 months $(95 \% \mathrm{CI}=5.165-9.235)$ and of those at stage IV was 6.2 months $(95 \% \mathrm{CI}=2.287-10.113)$, and the median OS of patients at stage III was 11.5 months (95\% CI $=10.313-12.687)$ and at stage IV was 9.4 months (95\% CI $=6.749-12.051$ ). The median PFS and the median OS of patients who had previously received radiotherapy were 7.5 months (95\% CI $=6.007-8.993)$ and 11.7 months (95\% CI $=10.705-12.695)$, respectively. The median PFS and the median OS of patients who had previously received nonradiotherapy were 6.2 months $(95 \% \mathrm{CI}=3.852-8.548)$ and 10.3 months (95\% CI $=8.578-12.022)$, respectively. There was a significant difference in PFS and OS for the cycles of treatment ( $P=0.004$ and $P=0.002$, respectively; Figure $2 \mathrm{~A}$ and $\mathrm{B})$. The median PFS of patients receiving less than three cycles was 4.9 months $(95 \% \mathrm{CI}=3.92-5.88$; Figure $2 \mathrm{~A}$ ) and of those receiving more than three cycles was 7.6 months (95\% CI $=6.601-8.599$; Figure 2A). The median OS of patients receiving less than three cycles was 8.9 months (95\% CI =6.94-10.86; Figure 2B) and of those receiving more than three cycles was 11.7 months $(95 \%$ $\mathrm{CI}=10.326$-13.074; Figure 2B).

\section{Toxicities}

In general, treatment-related toxicities from weekly nab-paclitaxel at the dose of $100 \mathrm{mg} / \mathrm{m}^{2}$ were mild to moderate, and no patient experienced a treatment-related death, a dose reduction, or a therapy discontinuation because of nab-paclitaxel-associated toxicities. Treatment-related AEs are presented in Table 5. No hypersensitivity reactions or treatment-related grade 4 AEs were reported. The major grade 3 toxicities were leukopenia (5\%), neutropenia (2\%), fatigue $(10 \%)$, and sensory neuropathy $(7 \%)$. Other treatmentrelated toxicities, including anemia, thrombocytopenia, febrile neutropenia, alopecia, anorexia, nausea, myalgia, and arthralgia, were well tolerated and easily managed.

\section{Discussion}

This is the first article to evaluate the anticancer effect and toxicity of weekly administered nab-paclitaxel as a secondline chemotherapy in treating elderly patients with advanced or metastatic squamous NSCLC. In this study, we retrospectively reviewed 42 elderly patients with relapsed NSCLC. Nab-paclitaxel was administered on days 1, 8, and 15 followed by 1 week of rest. This treatment protocol prolonged patient survival, with a median PFS of 6.6 months and a median OS of 10.9 months. The exact mechanisms behind the efficacy of nab-paclitaxel monotherapy are unknown. It is speculated that the improved survival is related to the

Table 5 Adverse effects of nab-paclitaxel monotherapy of 42 patients, $\mathrm{n}(\%)$

\begin{tabular}{llllll}
\hline Adverse effects & \multicolumn{5}{l}{ Maximum grade } \\
\cline { 2 - 6 } & All & I & $\mathbf{2}$ & $\mathbf{3}$ & $\mathbf{4}$ \\
\hline Hematologic & & & & & \\
Anemia & $16(38)$ & $14(33)$ & $2(5)$ & 0 & 0 \\
Leukopenia & $20(48)$ & $7(17)$ & II (26) & $2(5)$ & 0 \\
Neutropenia & $16(38)$ & $7(17)$ & $8(19)$ & $1(2)$ & 0 \\
Thrombocytopenia & $5(11)$ & $5(11)$ & 0 & 0 & 0 \\
Febrile neutropenia & $4(10)$ & $2(5)$ & $2(5)$ & 0 & 0 \\
Nonhematologic & & & & & \\
Alopecia & $28(67)$ & $12(29)$ & $16(38)$ & 0 & 0 \\
Fatigue & $24(58)$ & $10(24)$ & $10(24)$ & $4(10)$ & 0 \\
Sensory neuropathy & $25(59)$ & $16(38)$ & $6(14)$ & $3(7)$ & 0 \\
Anorexia & $12(29)$ & $8(19)$ & $4(10)$ & 0 & 0 \\
Nausea & $15(36)$ & $13(31)$ & $2(5)$ & 0 & 0 \\
Myalgia & $8(19)$ & $6(14)$ & $2(5)$ & 0 & 0 \\
Arthralgia & $11(26)$ & $8(19)$ & $3(7)$ & 0 & 0 \\
Hypersensitivity & 0 & 0 & 0 & 0 & 0 \\
\hline
\end{tabular}


fact that nab-paclitaxel drug levels increase with age. Similar results were found in a clinical trail of nab-paclitaxel in combination with carboplatin; in this study, the median OS for the subpopulation aged 70 years or older was prolonged compared with the median OS for younger patients. ${ }^{14}$ Another hypothesis is that the higher PFS and OS are related to the character and treatment protocol of nab-paclitaxel. Studies show that nab-paclitaxel utilizes albumin to deliver paclitaxel, resulting in a higher concentration relative to solventbased paclitaxel. ${ }^{15}$ Another possible contributing factor to the finding that nab-paclitaxel accumulates in the tumor is the prevalence of albumin-binding proteins, such as secreted protein, near the tumors that are acidic and rich in cysteine. ${ }^{16}$ An obvious advantage to weekly regimens is close monitoring and an improved safety profile on average. ${ }^{17}$ Another study of elderly patients with metastatic breast cancer similarly found that weekly nab-paclitaxel is safe and more efficacious than a every-3-week schedule. ${ }^{10}$ Furthermore, a meta-analysis revealed that weekly paclitaxel regimens show a more favorable toxicity profile than every-3-week paclitaxel administration. ${ }^{18}$ Because so few toxicities were experienced, the elderly patients in these studies showed better compliance, resulting in better PFS and OS. However, we cannot demonstrate that the schedule is effective for patients with poor PS owing to few patients $(9.52 \%)$.

In the subgroup analysis, there was no significant difference in efficacy if the patient had previously received a taxane agent. The exact reasons are unclear, though a possible explanation is that the first-line therapy failed owing to platinum resistance or taxane agent-sensitive relapse. The previous study had similar results in that the previous use of paclitaxel had no impact on the response or survival to subsequent docetaxel therapy. ${ }^{19}$ Although this difference in PFS and OS was not statistically significant for patients regardless of whether they had previously received radiotherapy, the median PFS and the median OS of these previously treated patients were prolonged by 1.3 and 1.4 months, respectively. A study revealed that nab-paclitaxel improved radiotherapy in a supra-additive manner, ${ }^{20}$ but no trail has evaluated the role of nab-paclitaxel after radiotherapy. Based on our results, patients with stage III were more likely to benefit from the schedule. On the one hand, the patients who received radiotherapy were mainly patients with stage III disease who had better OS. On the other hand, the previous radiotherapy alleviated the tumor burden and strengthened the control of local tumor so that second-line agents produced superior efficacy. Patients with stage IV disease were apt to select the best support treatment other than the second-line chemotherapy when the first-line chemotherapy failed. Therefore, patients with stage IV disease were fewer than those with stage III disease in this study. In this retrospective study, there was no significant difference in survival from the previous surgery. The study found that surgery history was not an important factor for survival.

In the present retrospective analysis, the survival of patients receiving less than three cycles of treatment was worse than that of those receiving more than three cycles of treatment. There was no patient who had CR or PR, but SD was higher (38.46\% vs $20.69 \%$ ). In contrast, nine patients receiving more than three cycles of monotherapy had PR. These results suggest that the efficacy of nab-paclitaxel is related to drug accumulation, such that partly SD may later lead to PR with prolonged treatment. Therefore, an evaluation of the anticancer effect of at least three cycles of treatment was warranted.

In terms of treatment-related toxicities, no severe hypersensitivity reactions or grade 4 AEs occurred. The common AEs were anemia, leukopenia, neutropenia, alopecia, fatigue, sensory neuropathy, nausea, anorexia, arthralgia, and arthralgia. Grade 3 AEs were leukopenia, neutropenia, fatigue, and sensory neuropathy. No patients were compelled to reduce their dose or delay treatment because of treatmentrelated toxicities, which is consistent with the findings in published literature on this subject. ${ }^{19}$ Even nab-paclitaxel proved beneficial and tolerable in patients with advanced NSCLC and mild and moderate renal impairment. ${ }^{21}$ Except for the medicinal properties of nab-paclitaxel, ${ }^{22}$ the benefit and tolerability of this line of therapy may be related to a smaller dose of each individual administration. On the whole, the treatment-related AEs experienced with the weekly schedule were relatively mild and controllable in elderly patients with squamous NSCLC.

As the treatment of advanced NSCLC has evolved over the past decade, advances in the treatment of squamous NSCLC have lagged. Currently, there is no special drug for the treatment of elderly patients with refractory advanced or metastatic squamous NSCLC. Several recently concluded trials of antiangiogenic agents and other biologically targeted treatments could represent the way to improve survival expectancy for these patients. A prospective Phase III trial with a combination arm of ramucirumab (a human IgG1 monoclonal antibody) and docetaxel and a single-agent arm of docetaxel alone revealed a significantly higher ORR (23\% and $14 \%, P<0.001$ ) and longer survival (9.5 vs 8.2 months) for relapsed stage IV squamous NSCLC. ${ }^{23}$ The other Phase II, single-arm trial of nivolumab (a fully human IgG4 PD-1 immune checkpoint inhibitor antibody) showed promising ORR (14.5\%) and median OS (8.2 months) for those patients whose median age was 65 years. ${ }^{24}$ Although therapies with 
the new drugs have achieved higher OS than others, they are currently not administered clinically because of their relative high cost and indefinite activity. The efficacy and safety of these new drugs require further study.

\section{Conclusion}

Treatment options for patients with relapsed squamous NSCLC are limited, and elderly patients are often undertreated owing to toxicity concerns. Our study finds that weekly administered nab-paclitaxel monotherapy is an effective and safe regimen for this population, especially for patients with stage III disease or good PS. From our singleinstitution analysis, we find that the efficacy of nab-paclitaxel is related to drug accumulation. Therefore, the anticancer effect can be evaluated after at least three cycles of treatment. Because our retrospective analysis had a small sample size, however, a prospective, large sample, multicenter clinical study is needed to verify these results.

\section{Disclosure}

The authors report no conflicts of interest in this work.

\section{References}

1. Socinski MA, Evans T, Gettinger S, et al. Treatment of stage IV nonsmall cell lung cancer: diagnosis and management of lung cancer, $3 \mathrm{rd}$ ed: American College of Chest Physicians evidence-based clinical practice guidelines. Chest. 2013;143(5 suppl):341s-368s.

2. Howlader N, Noone AM, Krapcho M, et al, editors. SEER Cancer Statistics Review, 1975-2010. Bethesda, MD: National Cancer Institute; 2013.

3. Carnio S, Novello S, Mele T, Levra MG, Scagliotti GV. Extending survival of stage IV non-small cell lung cancer. Semin Oncol. 2014;41(1):69-92.

4. John V, Mashru S, Lichtman SM. Pharmacological factors influencing anticancer drug selection in the elderly. Drugs Aging. 2003;20(10):737-759.

5. Sun Y, Wu YL, Zhou CC, et al. Second-line pemetrexed versus docetaxel in Chinese patients with locally advanced or metastatic non-small cell lung cancer: a randomized, open-label study. Lung Cancer. 2013;79(2):143-150.

6. Garassino MC, Martelli O, Broggini M, et al; TAILOR Trialists. Erlotinib versus docetaxel as second-line treatment of patients with advanced non-small-cell lung cancer and wild-type EGFR tumours (TAILOR): a randomised controlled trial. Lancet Oncol. 2013;14(10):981-988.

7. Palumbo R, Sottotetti F, Trifirò G, et al. Nanoparticle albumin-bound paclitaxel (nab-paclitaxel) as second-line chemotherapy in her 2-negative, taxane-pretreated metastatic breast cancer patients: prospective evaluation of activity, safety, and quality of life. Drug Des Devel Ther. 2015;9: 2189-2199.

8. Rizvi NA, Riely GJ, Azzoli CG, et al. Phase I/II trial of weekly intravenous 130-nm albumin-bound paclitaxel as initial chemotherapy in patients with stage IV non-small-cell lung cancer. J Clin Oncol. 2008;26(4):639-643.

Clinical Interventions in Aging

\section{Publish your work in this journal}

Clinical Interventions in Aging is an international, peer-reviewed journal focusing on evidence-based reports on the value or lack thereof of treatments intended to prevent or delay the onset of maladaptive correlates of aging in human beings. This journal is indexed on PubMed Central, MedLine,
9. Socinski MA, Langer CJ, Okamoto I, et al. Safety and efficacy of weekly $n^{\circledR}{ }^{\circledR}$-paclitaxel in combination with carboplatin as first-line therapy in elderly patients with advanced non-small-cell lung cancer. Ann Oncol. 2013;24(2):314-321.

10. Aapro M, Tjulandin S, Bhar P, Gradishar W. Weekly nab-paclitaxel is safe and effective in 65 years old patients with metastatic breast cancer: a post-hoc analysis. Breast. 2011;20(5):468-474.

11. Green MR, Manikhas GM, Orlov S, et al. Abraxane, a novel Cremophorfree, albumin-bound particle form of paclitaxel for the treatment of advanced non-small-cell lung cancer. Ann Oncol. 2006;17(8): $1263-1268$.

12. Zheng Q, Yao Y, Nan K. Weekly intravenous nanoparticle albuminbound paclitaxel for elderly patients with stage IV non-small-cell lung cancer: a series of 20 cases. J Biomed Res. 2012;26(3):159-164.

13. Therasse P, Arbuck SG, Eisenhauer EA, et al. New guidelines to evaluate the response to treatment in solid tumors. European Organization for Research and Treatment of Cancer, National Cancer Institute of the United States, National Cancer Institute of Canada. J Natl Cancer Inst. 2000; 92(3):205-216.

14. Socinski MA, Bondarenko I, Karaseva NA, et al. Weekly nab-paclitaxel in combination with carboplatin versus solvent-based paclitaxel plus carboplatin as first-line therapy in patients with advanced non-smallcell lung cancer: final results of a phase III trial. J Clin Oncol. 2012; 30(17):2055-2062.

15. Gupta N, Hatoum H, Dy GK. First line treatment of advanced nonsmall-cell lung cancer-specific focus on albumin bound paclitaxel. Int J Nanomedicine. 2014;9:209-221.

16. Yardley DA. nab-Paclitaxel mechanisms of action and delivery. $J$ Control Release. 2013;170(3):365-372.

17. Joerger M. Metabolism of the taxanes including nab-paclitaxel. Expert Opin Drug Metab Toxicol. 2015;11(5):691-702.

18. Huang TC, Campbell TC. Comparison of weekly versus every 3 weeks paclitaxel in the treatment of advanced solid tumors: a meta-analysis. Cancer Treat Rev. 2012;38(6):613-617.

19. Goto Y, Sekine I, Yamada K, et al. Influence of previous chemotherapy on the efficacy of subsequent docetaxel therapy in advanced non-small cell lung cancer patients. $J$ Thorac Oncol. 2008;3(4):412-416.

20. Wiedenmann N, Valdecanas D, Hunter N, et al. 130-nm Albumin bound paclitaxel enhances tumor radiocurability and therapeutic gain. Clin Cancer Res. 2007;13(6):1868-1874.

21. Langer CJ, Hirsh V, Ko A, Renschler MF, Socinski MA. Weekly nabpaclitaxel in combination with carboplatin as first-line therapy in patients with advanced non-small-cell lung cancer: analysis of safety and efficacy in patients with renal impairment. Clin Lung Cancer. 2015;16(2): $112-120$.

22. Simon GR. nab-Paclitaxel for the treatment of advanced squamous non-small-cell lung cancer: a comprehensive update. Clin Lung Cancer. 2014;15(6):391-397.

23. Garon EB, Ciuleanu TE, Arrieta O, et al. Ramucirumab plus docetaxel versus placebo plus docetaxel for second-line treatment of stage IV non-small-cell lung cancer after disease progression on platinum-based therapy (REVEL): a multicentre, double-blind, randomised phase 3 trial. Lancet. 2014;384(9944):665-673.

24. Brahmer J, Reckamp KL, Baas P, et al. Nivolumab versus docetaxel in advanced squamous-cell non-small-cell lung cancer. NEngl JMed.2015; 373(2):123-135.

CAS, Scopus and the Elsevier Bibliographic databases. The manuscript management system is completely online and includes a very quick and fair peer-review system, which is all easy to use. Visit http://www.dovepress. com/testimonials.php to read real quotes from published authors. 